\title{
A compendium of animal bibliographies
}

The US Department of Agriculture's (USDA's) National Agricultural Library (NAL) is the home of its Animal Welfare Information Center (AWIC), a congressionally mandated service included in the 1985 amendments to the Animal Welfare Act (AWA). A quaint 1989 video on the website's 'About AWIC' page gives the history of the Center, opened in 1986, and its charge to provide information on the 3Rs: reduction, refinement and replacement of animals in research.

AWIC provides bibliographies based on its extensive holdings of materials on animal care and use and on the use of alternatives. These bibliographies are highlighted on the AWIC homepage, in the 'Publications' tab and the 'News and Events' tab, under 'New Publications'. Some bibliographies are highlighted under 'Spotlights' on the homepage or by clicking 'More' next to 'Spotlights'.

A visit to the 'Publications' tab at the top of the page leads to lists of bibliographies prepared by AWIC. There are compendia of references on elephants, cats, big cats, rabbits, rodents, zebrafish, swine, molluscs and many other groups of animals. A few are relatively recent, such as those on Old World camels, elephants and zebrafish; some have been updated recently, such as those on cats and horses; and others have not been updated since the 1990s. There are bibliographies on zoonotic diseases; environmental enrichment; humans and animals in history; legislation and guidelines; techniques, methodologies and procedures; and teaching and education. There are publications from the National Institute of Food and Agriculture and two Spanish-language publications, including the Guide for the Care and Use of Laboratory Animals.

Links to the NAL explain how someone who is otherwise unable to locate a reference that appears in the bibliographies may use the services of NAL to obtain a copy of the publication. There is a fee for these services, which is waived for employees of USDA and a few exempt organizations.

Because this is a government website and is required to cover regulatory along with alternatives information, it is complete and complex. The homepage leads the visitor in many different directions. 'Spotlights', just below the 'Home' logo (missing from the screen shot above), links to the US Department of Health and Human Service's National Toxicology Program list of US and International Acceptance of Alternative Methods, 1998-2012. That page, in turn, leads the visitor to the Interagency Coordinating Committee on the Validation of Alternative Methods. That site may be discussed in a future review. The next 'Spotlight' down leads to a 150-page publication, Swine Anesthesia and Analgesia, 2000-2010.

The third link under 'Spotlights' leads to the USDA Animal and Plant Health Inspection Service (APHIS) Animal Welfare page on

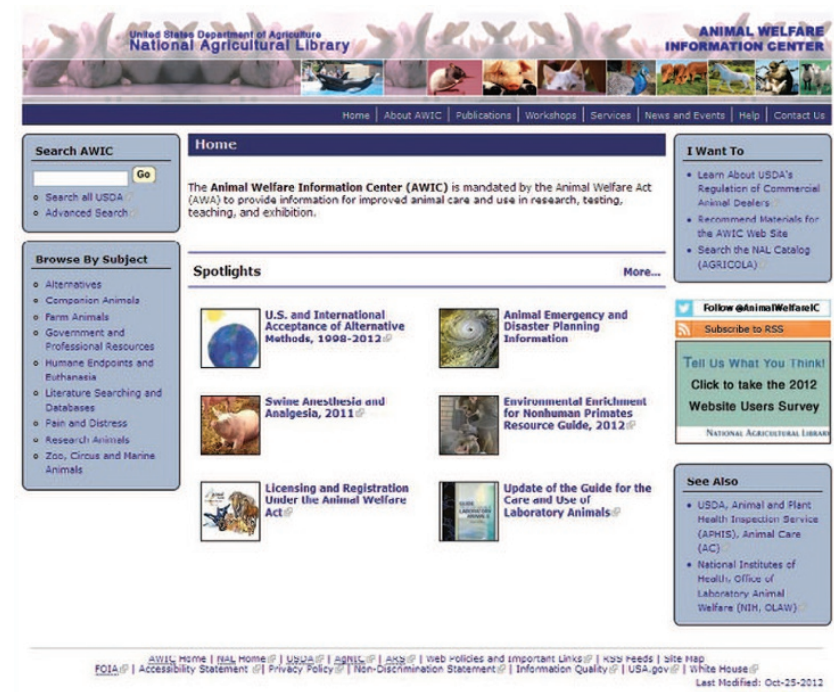

'Licensing and Registration'. APHIS is in charge of licensing and registration of businesses or activities under the AWA and is also the USDA's inspection and enforcement arm for these registered entities.

Also under 'Spotlights' is a newly updated bibliography, Environmental Enrichment for Nonhuman Primates Resource Guide, which also is listed under the 'Publications' tab. This is a compendium of documents related to nonhuman primate enrichment, a linked bibliography leading to many other sources and links to websites.

'Animal Emergency and Disaster Planning Information', under 'Spotlights', leads to a page that will allow the visitor to click 'Research Animals', linking to publications, a bibliography and websites.

Browsing by subject, using the box on the left-hand side of the page, will lead to more publications and links, such as those on 'Alternatives', which contains a link to a document on alternatives from the EU Joint Research Centre, another to the Canadian Council on Animal Care and a third to AWIC's partner, the Johns Hopkins Center for Alternatives to Animal Testing.

There are many ways to reach each page, many links on the pages and, of course, the bibliographies, new and old.

We highly recommend this site for its vast amount of information for laboratory animal researchers, animal care personnel and others who are interested in learning more about animals. We only wish some of the bibliographies were more recent.

\section{http://awic.nal.usda.gov/}
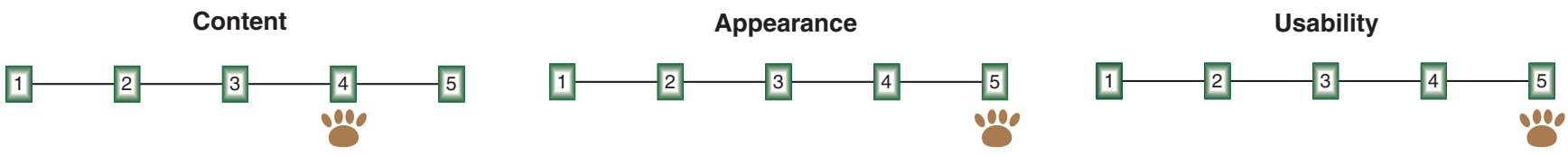